\title{
Concentrations and patterns of polychlorinated biphenyls at different process stages of cement kilns co-processing waste incinerator fly ash
}

\author{
Guorui Liu ${ }^{\mathrm{a}, \mathrm{b}, *}$, Lili Yang ${ }^{\mathrm{a}, \mathrm{b}}$, Jiayu Zhan ${ }^{\mathrm{c}}$, Minghui Zheng ${ }^{\mathrm{a}, \mathrm{b}}, \mathrm{Li} \mathrm{Li}^{\mathrm{a}}$, Rong Jin ${ }^{\mathrm{a}, \mathrm{b}}$, Yuyang Zhao ${ }^{\mathrm{a}, \mathrm{b}}$, Mei Wang ${ }^{\mathrm{a}, \mathrm{b}}$ \\ a State Key Laboratory of Environmental Chemistry and Ecotoxicology, Research Center for Eco-Environmental Sciences, Chinese Academy of Sciences, Beijing 100085, China \\ ${ }^{\mathrm{b}}$ University of Chinese Academy of Sciences, Beijing 100049, China \\ ' State Key Laboratory of Solid Waste Reuse for Building Materials, Beijing Building Materials Academy of Sciences Research, Beijing 100041, China
}

\section{A R T I C L E I N F O}

\section{Article history:}

Received 9 May 2016

Revised 8 September 2016

Accepted 11 September 2016

\section{Keywords:}

Polychlorinated biphenyls

Dioxin-like compounds

Fly ash

Waste incineration

Cement kiln

Persistent organic pollutants

\begin{abstract}
A B S T R A C T
Cement kilns can be used to co-process fly ash from municipal solid waste incinerators. However, this might increase emission of organic pollutants like polychlorinated biphenyls (PCBs). Knowledge of PCB concentrations and homolog and congener patterns at different stages in this process could be used to assess the possibility of simultaneously controlling emissions of polychlorinated dibenzo- $p$-dioxins and dibenzofurans (PCDD/Fs) and "dioxin-like" compounds. To date, emissions from cement kilns coprocessing fly ash from municipal solid waste incinerators have not been analyzed for PCBs. In this study, stack gas and particulate samples from two cement kilns co-processing waste incinerator fly ash were analyzed for PCBs. The average total tri- to deca-chlorinated biphenyl $\left(\sum_{3-10} \mathrm{PCB}\right)$ concentration in the stack gas samples was $10.15 \mathrm{ng} \mathrm{m}^{-3}$. The $\sum_{3-10} \mathrm{PCB}$ concentration ranges in particulate samples from different stages were $0.83-41.79 \mathrm{ng} \mathrm{g}^{-1}$ for cement kiln 1 and $0.13-1.69 \mathrm{ng} \mathrm{g}^{-1}$ for cement kiln 2 . The $\sum_{3-}$ ${ }_{10} \mathrm{PCB}$ concentrations were much higher in particulate samples from the suspension pre-heater boiler, humidifier tower, and kiln back-end bag filters than in particulate samples from other stages. For these three stages, PCBs contributed to $15-18 \%$ of the total PCB, PCDD/F, and polychlorinated naphthalene toxic equivalents in stack gases and particulate matter. The PCB distributions were similar to those found in other studies for PCDD/Fs and polychlorinated naphthalenes, which suggest that it may be possible to simultaneously control emissions of multiple organic pollutants from cement kilns. Homolog patterns in the particulate samples were dominated by the pentachlorobiphenyls. CB-105, CB-118, and CB-123 were the dominant dioxin-like PCB congeners that formed at the back-end of the cement kiln. A mass balance of PCBs in the cement kilns indicated that the total mass of PCBs in the stack gases and clinker was about half the mass of PCBs in the raw materials.
\end{abstract}

(c) 2016 Elsevier Ltd. All rights reserved.

\section{Introduction}

Polychlorinated biphenyls (PCBs) have adverse effects on the environment and human health, which resulted in their inclusion in the initial list of chemicals in the Stockholm Convention on Persistent Organic Pollutants (POPs). The production of technical PCB mixtures for use in capacitors, transformers, and other applications has been banned internationally (Breivik et al., 2007; Diamond et al., 2010; Hornbuckle and Robertson, 2010; Hu and Hornbuckle, 2010). However, PCBs can be unintentionally produced and released to the environment during many industrial thermal activities (Liu et al., 2013b).

\footnotetext{
* Corresponding author at: State Key Laboratory of Environmental Chemistry and Ecotoxicology, Research Center for Eco-Environmental Sciences, Chinese Academy of Sciences, Beijing 100085, China.

E-mail address: grliu@rcees.ac.cn (G. Liu).
}

Since the banning of production and use of technical PCB mixtures, the unintentional release of PCBs during industrial thermal processes has increased in relative importance as a source of PCBs to the environment. Waste incineration is an important source of unintentionally produced PCBs because solid waste is often incompletely combusted in waste incinerators (Abad et al., 1999; Sakai et al., 2006; Jansson et al., 2008; Jansson and Andersson, 2012; Khumsaeng et al., 2013). A large proportion of the PCBs that are unintentionally produced during waste incineration are released in fly ash. In earlier research, the total concentration range for twelve dioxin-like PCB (dl-PCB) congeners in fly ash from waste incinerators was of $1.10-60 \mathrm{ng} \mathrm{g}^{-1}$, and the associated toxic equivalency (TEQ) range was $0.039-1.2 \mathrm{ng} \mathrm{g}^{-1}$ (Tabata et al., 2013). Therefore, fly ash from municipal solid waste incinerators (MSWIs) can contain high concentrations of PCBs, and appropriate methods are required for safe disposal of this ash. 
In China, huge quantities of MSWI fly ash are produced by waste incinerators (Liu et al., 2015), and disposal of this ash is challenging. Cement kilns have been used to destroy waste containing organic chemicals because these pollutants effectively decompose at kiln temperatures above $1000^{\circ} \mathrm{C}$. Emission of contaminants from cement plants and the risks posed to the surrounding environment and human health have attracted increasing attention (Schuhmacher et al., 2002, 2004; Garcia-Perez et al., 2015). The risk of increased emission of organic pollutants to the environment needs to be investigated before cement kilns are used to coprocess solid wastes. Several studies have reported on the use of cement kilns for destruction of sewage sludge and soil contaminated with pesticides or polybrominated diphenyl ethers (Conesa et al., 2011; Yang et al., 2012). Other studies have investigated the emission of polychlorinated dibenzo-p-dioxins and dibenzofurans (PCDD/Fs) from cement kilns used to co-process solid waste (Wurst and Prey, 2003; Conesa et al., 2011; Yang et al., 2012). Unintentional formation and emission of PCBs and PCDD/Fs have been confirmed for many industrial thermal processes (Liu et al., 2009, 2013a; Lv et al., 2011; Nie et al., 2011, 2012). These earlier results suggest that $\mathrm{PCBs}$ will form in and be emitted from cement kilns co-processing solid waste. However, few studies have evaluated stack gas emissions of PCBs from cement kilns co-processing solid waste. To the best of our knowledge, only one study has investigated the long-term emissions of PCBs from a clinker kiln using alternative fuels, and analyses were performed for only twelve dl-PCB congeners (Rivera-Austrui et al., 2014). To date, no studies have investigated the emission, distribution within the kiln system, and homolog and congener patterns of PCBs for cement kilns co-processing MSWI fly ash.

We have previously studied the formation and distribution of PCDD/Fs and polychlorinated naphthalenes (PCNs) in two cement kilns co-processing MSWI fly ash, and the emissions of PCDD/Fs and PCNs from these kilns (Liu et al., 2015, 2016). However, the distributions within the kiln and homolog and congener patterns of PCBs have not been described. An understanding of the distributions within the kiln and homolog and congener patterns of PCBs, and comparison of the behaviors of PCBs with those of PCDD/Fs and PCNs, could be used to develop techniques for simultaneously controlling multiple pollutants. In this study, PCB concentrations were determined in stack gas samples and particulate samples from different process stages of the same two cement kilns as in our earlier research. The aim of this study was to clarify the distributions within the kiln and homolog and congener patterns of PCBs, and to evaluate the possibility of simultaneous control of $\mathrm{PCB}, \mathrm{PCDD} / \mathrm{F}$, and PCN emissions.

\section{Materials and methods}

\subsection{The cement kilns and sample collection}

The pilot cement kilns the samples were collected from are described in detail in our earlier research (Liu et al., 2015, 2016). Cement kilns 1 and 2 had daily clinker outputs of about 2000 and $2500 \mathrm{t}$, respectively. Kiln 1 had been used to continuously co-process MSWI fly ash at a rate of $20 \mathrm{t} \mathrm{d}^{-1}$ for about $300 \mathrm{~d}$. Kiln 2 had not previously been used to co-process MSWI fly ash, and was studied to evaluate the effect of long-term treatment of MSWI fly ash on the formation of PCBs in kiln 1 (Liu et al., 2015, 2016). The chemical composition of MSWI fly ash added into the cement kilns was determined by X-ray fluorescence (Table S1).

Stack gases released from the back end of kiln 1 were collected using an automatic isokinetic sampling method described in detail elsewhere (Ba et al., 2010; Liu et al., 2010; Lv et al., 2011). Particulate samples were collected from different process stages of the kiln systems. A diagram showing the processes that occur in a cement kiln, and further information on the locations for sample collection is included in our earlier research (Liu et al., 2015, 2016). Kiln back-end particulate samples from the cyclone preheater outlet, suspension pre-heater boilers, humidifier towers, raw mill, bag filters were labeled as Ck-p1, Ck-p2, Ck-p3, Ck-p4 and $\mathrm{Ck}-\mathrm{p} 5$, respectively. Kiln head particulate samples from the boiler, clinker area, and bag filter were labeled Ck-p6, Ck-p7, and Ck-p8, respectively.

\subsection{Sample pretreatment and instrumental analysis for PCBs in stack gas and particulate samples}

PCB congeners in the samples were identified and quantified by isotope dilution high-resolution gas chromatography combined with high resolution mass spectrometry. The extraction, purification, and instrumental analysis of PCBs in samples are described in our previous studies (Liu et al., 2009, 2013a,b). Briefly, each sample was spiked with known amounts of ${ }^{13} \mathrm{C}_{12}$-labeled PCB internal standards (1668B-LCS), and then digested with $1 \mathrm{~mol} \mathrm{~L}^{-1} \mathrm{HCl}$. Each sample was Soxhlet extracted using toluene for $24 \mathrm{~h}$, then the extract was concentrated under reduced pressure. Each extract was purified first with silica gel treated with $44 \%$ (mass fraction) sulfuric acid, a multilayer silica gel column, and then a basic alumina column. The extract was finally concentrated to about $20 \mu \mathrm{L}$ under a gentle stream of nitrogen gas. Then, ${ }^{13} \mathrm{C}_{12}$-labeled PCB injection standards (1668B-IS) were added to evaluate the recoveries of the ${ }^{13} \mathrm{C}_{12}$-labeled internal standards.

The high-resolution gas chromatography combined with high resolution mass spectrometry used a DB-5 ms fused-silica column ( $60 \mathrm{~m} \times 0.25 \mathrm{~mm}$ i.d., $0.25 \mu \mathrm{m}$ film thickness). The mass spectrometer was operated in selected ion monitoring mode with a resolution of around 10,000 , and the most abundant ions in the molecular ion cluster were monitored (Liu et al., 2009, 2013a,b).

\subsection{Quality assurance and quality control of $P C B$ analysis}

Each selected PCB congener was identified by comparing the retention time of a selected chromatographic peak with the retention time of the same peak for the appropriate ${ }^{13} \mathrm{C}_{12}$-labeled standard. For quantification, the ratio of the target ion to qualification ion should be within $15 \%$ of the theoretical value. The range for recovery of the ${ }^{13} \mathrm{C}_{12}$-labeled PCB internal standard was $43-136 \%$. Laboratory blanks were analyzed with each batch of samples. The CB-28 and CB-101 concentrations in the blanks were slightly higher than the limits of detection but much lower than $5 \%$ of the concentrations in the samples. Therefore, the PCB concentrations in the samples were not blank corrected.

\section{Results and discussion}

\subsection{Emissions of PCBs in stack gases produced by cement kilns co- processing MSWI fly ash}

The PCB concentration range in the stack gas samples collected from the cement kilns was 61.2-110.4 $\mathrm{ng} \mathrm{m}^{-3}$ (average $87.2 \mathrm{ng} \mathrm{m}^{-3}$, relative standard deviation (RSD) $28.4 \%$ ). The dl-PCB concentration range in the stack gas samples was 0.39$0.91 \mathrm{ng} \mathrm{m}^{-3}$ (average $0.66 \mathrm{ng} \mathrm{m}^{-3}$, RSD 40\%), and the indicator PCB concentration range was $1.20-1.56 \mathrm{ng} \mathrm{m}^{-3}$ (average $1.38 \mathrm{ng} \mathrm{m}^{-3}$, RSD 13.0\%). The PCB TEQs were calculated using published toxic equivalency factors (TEFs) for PCBs (Van den Berg et al., 1998). The PCB TEQ range in the stack gas samples was 5.33-

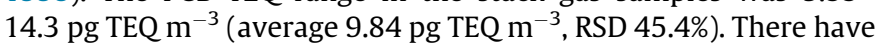
been few studies of stack gas emissions of PCBs from cement kiln 
co-processing solid waste. A long-term study of stack gas samples from a clinker kiln using alternative fuels gave a PCB TEQ range of 0.02-0.9 pg TEQ $\mathrm{m}^{-3}$ (Rivera-Austrui et al., 2014), which was lower than the range obtained in the present study.

The PCB homolog and congener patterns in the stack gas samples from the cement kilns co-processing MSWI fly ash were compared (Fig. S1). The tetrachlorinated PCBs dominated the PCB homologs, and the trichlorinated and pentachlorinated PCBs were the next most abundant homologs. Several dl-PCB congeners, including CB-77, CB-105, CB-118, and CB-126, contributed more than the other dl-PCB congeners to the total PCB concentrations in the stack gas samples. $\mathrm{CB}-28$ was the dominant indicator $\mathrm{PCB}$ congener. The $\mathrm{CB}-52, \mathrm{CB}-101$, and $\mathrm{CB}-138$ concentrations were higher than the CB-153 and CB-180 concentrations. By contrast, an earlier study of a technical PCB mixture that was manufactured in China (Zhang et al., 2009) found that trichlorinated PCBs were dominant and CB-77 contributed less than CB-105 (Zhang et al., 2009). These differences among congener patterns could be helpful in identifying specific sources of PCBs found in the environment.

\subsection{Distributions of PCBs in particulate samples collected from} different stages in the cement kilns co-processing MSWI fly ash

The PCB concentrations and the distribution of PCBs homologs within particulate matter produced at different stages of the cement kiln process can be compared to determine the main stages for formation of PCBs. The PCB concentrations and homolog patterns in the particulate samples from different process stages of the cement kilns in the two cement kilns in the present study were compared (Fig. 1). The PCB mass concentration in the cyclone preheater outlet sample ( $\mathrm{Ck}-\mathrm{p} 1)$ was $5.2 \mathrm{ng} \mathrm{g}^{-1}$. The mass concentrations of PCBs in the suspension pre-heater boiler ( $\mathrm{Ck}-\mathrm{p} 2)$, humidifier tower (Ck-p3), and $\mathrm{Ck}$-p5 samples were 23.9, 21.2, and $41.8 \mathrm{ng} \mathrm{g}^{-1}$, respectively. PCB mass concentrations of less than $2.5 \mathrm{ng} \mathrm{g}^{-1}$ were found in the particulate samples from the other parts of the kiln system. These results show the PCB concentrations were higher in the particulate samples from the suspension preheater boilers ( $\mathrm{Ck}-\mathrm{p} 2)$, humidifier towers ( $\mathrm{Ck}-\mathrm{p} 3)$, and bag filters (Ck-p5) at the kiln back-ends than in samples from other parts of the kilns. This suggests that these process stages might be major sites for formation of PCBs in the cement kiln system. This knowledge could aid the development of techniques for controlling the formation and emission of PCBs in the key stages of a cement kiln when it is used to co-process MSWI fly ash.

The PCB distributions in the particulate samples from different parts of the kilns were similar to the PCDD, PCDF, and PCN distri-

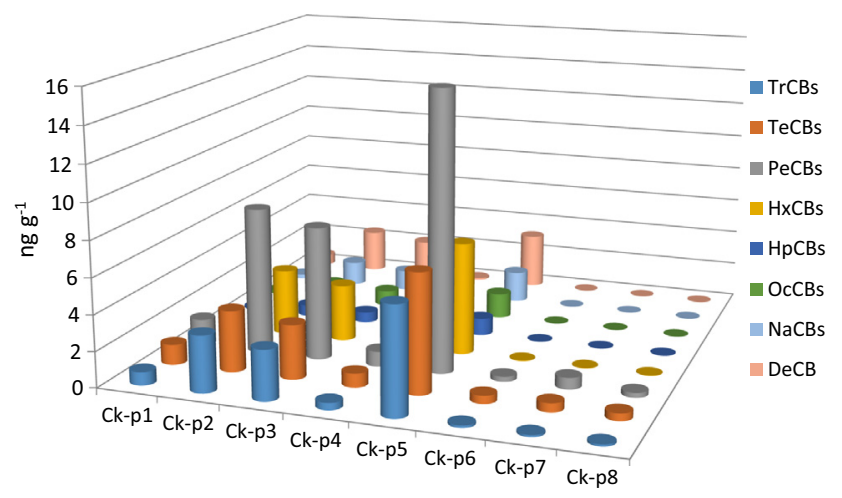

Fig. 1. Polychlorinated biphenyl concentrations and homolog patterns in particulate samples (labeled $\mathrm{Ck}$-p1 to $\mathrm{Ck}$-p8) from different process stages in cement kiln 1 (CBs = chlorobiphenyls, $\mathrm{Tr}=$ tri, $\mathrm{Te}=$ tetra, $\mathrm{Pe}=$ penta, $\mathrm{Hx}=$ hexa, $\mathrm{Hp}=$ hepta, $\mathrm{Oc}=$ octa, $\mathrm{Na}=$ nona, and $\mathrm{De}=$ deca $)$. butions that we previously found in cement kilns co-processing MSWI fly ash (Liu et al., 2015, 2016). Because the major sites of PCB formation in the cement kilns were same for PCDDs, PCDFs, and PCNs, it should be possible to develop techniques for simultaneously controlling formation of PCBs and other unintentionally produced POPs.

\subsection{Comparisons of $P C B$ concentrations and TEQs in samples from kilns 1 and 2}

Larger amounts of unintentionally produced POPs may be formed in and emitted from thermal facilities that have operated for a long time than are formed in and emitted from new facilities (Weber et al., 2002; Cunliffe and Williams, 2009; Li et al., 2011). Particulate samples from different process stages in cement kiln 2, which had not been used for co-processing MSWI waste previously, were used to evaluate the potential effects of long-term thermal treatment of MSWI fly ash on the formation of PCBs in cement kiln 1 . Cement kilns 1 and 2 were very similar and were operated using similar parameters (Liu et al., 2015, 2016). Moreover, in the pilot tests, the same batch of MSWI fly ash was destroyed in kilns 1 and 2 (Liu et al., 2015, 2016). The PCB concentrations and TEQs found in the particulate samples from different process stages of kilns 1 and 2 are displayed in Fig. 2. The PCB mass concentrations and TEQs were higher in the kiln 1 samples than in the kiln 2 samples. There were larger differences between the concentrations in the kiln 1 and 2 samples for samples from sites Ckp2, Ck-p3, and Ck-p5 than there were for the other samples. This was further evidence that the suspension pre-heater boiler $(\mathrm{Ck}$ p2), humidifier tower (Ck-p3), and kiln back-end bag filters ( $\mathrm{Ck}$ p5) were major sites for formation of PCBs in cement kilns coprocessing MSWI fly ash. We previously found very similar results for PCDD/Fs and PCNs (Liu et al., 2015, 2016).

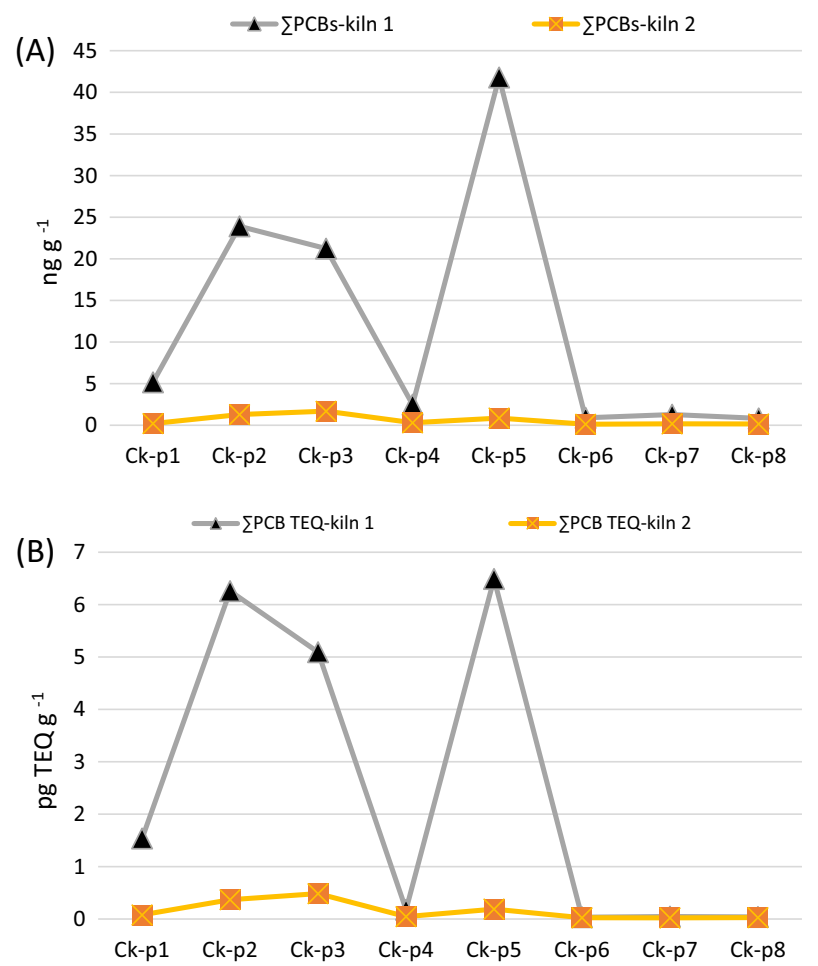

Fig. 2. Total polychlorinated biphenyl $\left(\sum \mathrm{PCB}\right)(\mathrm{A})$ mass concentrations and $(\mathrm{B})$ toxic equivalent (TEQ) concentrations in particulate samples from cement kilns 1 and 2 . 
Solid residues, such as fly ash, deposited in industrial thermal facilities can catalyze the formation of unintentionally produced POPs to a maximum extent of two orders of magnitudes (Jiang et al., 2015a,b; Wang et al., 2015). Therefore, long-term accumulation of solid particles in the cement kiln 1 system, especially at the cyclone preheater outlet, suspension preheater boiler, humidifier tower, and back-end bag filter, might be an important contributor to the higher concentrations of PCBs at these sites in cement kiln 1 than in kiln 2. Periodic removal of solid residues deposited in these areas in cement kiln 1 might simultaneously reduce the formation of PCDD/Fs and dioxin-like compounds, including PCBs and PCNs (Liu et al., 2015, 2016).

\subsection{Homolog and congener profiles of PCBs in particulate samples} from different stages in the cement kilns

Homolog and congener profiles of PCBs can improve our understanding of the formation of PCBs in cement kilns co-processing MSWI fly ash. In this study, pentachlorinated PCBs dominated the particulate sample homolog patterns, and the next most abundant homologs were the trichlorinated, tetrachlorinated, and hexachlorinated PCBs (Fig. 1). The PCB homolog patterns in particulate samples from different process stages were generally similar. However, these homolog patterns were slightly different from those observed in the stack gas samples, and this could be caused by differences in the partitioning behavior of different homologs between the particle and stack gas phases. The tetrachlorinated PCBs were dominant in stack gas samples.

The dl-PCB and indicator PCB congener profiles in the particulate samples from different parts of the cement kilns are presented in Fig. 3. Four congeners, CB-77, CB-105, CB-118, and CB-123, dominated the $12 \mathrm{dl}-\mathrm{PCB}$ congeners in the particulate samples.
Together these four congeners contributed about $80 \%$ of the total dl-PCB concentrations. This was similar to the dl-PCB pattern in stack gas from a clinker kiln using alternative fuels (RiveraAustrui et al., 2014). Three congeners, CB-28, CB-101, and CB153 , contributed much more than the other indicator congeners to the total indicator PCB congener concentrations. Together, CB28 , CB-101, and CB-153 contributed about $80 \%$ of the total indicator PCB concentrations. Different dl-PCB and indicator PCB congener profiles were found in particulate samples from different process stages in the kiln system. The dl-PCB and indicator PCB congener patterns in the Ck-p1, Ck-p2, Ck-p3, Ck-p4, and Ck-p5 samples were very similar, but different patterns were found in the Ck-p6, Ck-p7, and Ck-p8 samples. CB-77 contributed much more to the total dl-PCB concentrations in the Ck-p6, Ck-p7, and Ck-p8 samples than in the samples from the other process stages. By contrast, CB-118, CB-123, and CB-105 contributed much less to the total dl-PCB concentrations in the Ck-p6, Ck-p7, and Ck-p8 samples than in the samples from the five other process stages. The Ck-p6, Ck-p7, and Ck-p8 sampling sites were the kiln head boiler, the clinker area, and the kiln head bag filter, respectively. PCBs were mainly formed in the processes occurring around the kiln back-end. Therefore, the differences among the congener patterns in the samples from different parts of the kilns suggest that $\mathrm{CB}-$ $105, \mathrm{CB}-118$, and $\mathrm{CB}-123$ are the dominant dl-PCB congeners formed at the kiln back-end. Similarly, the indicator PCB patterns in the samples from different process stages of the kiln system led us to speculate that CB-101, CB-138, and CB-153 were the dominant indicator congeners formed at the kiln back-end. These comparisons suggest reduction of PCB formation in cement kilns coprocessing MSWI fly ash should focus on several major congeners, including CB-105, CB-118, CB-123, CB-101, CB-138, and CB-153.

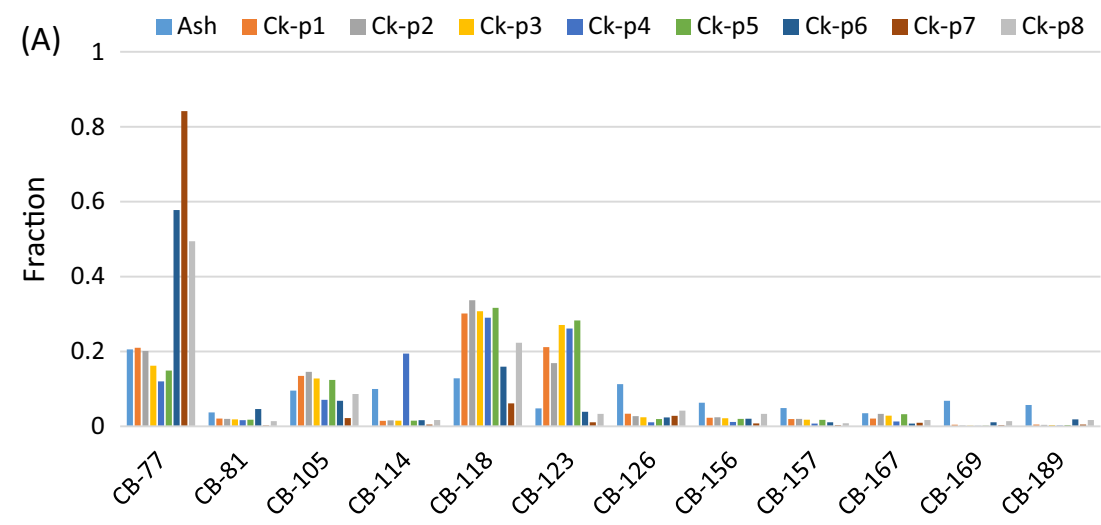

(B)

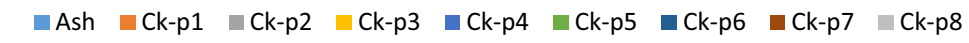

1

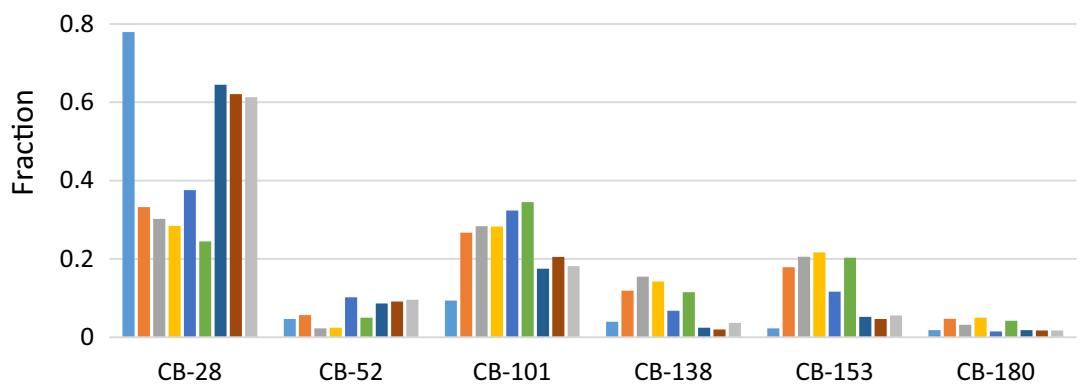

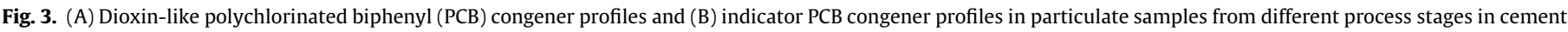
kiln 1. 


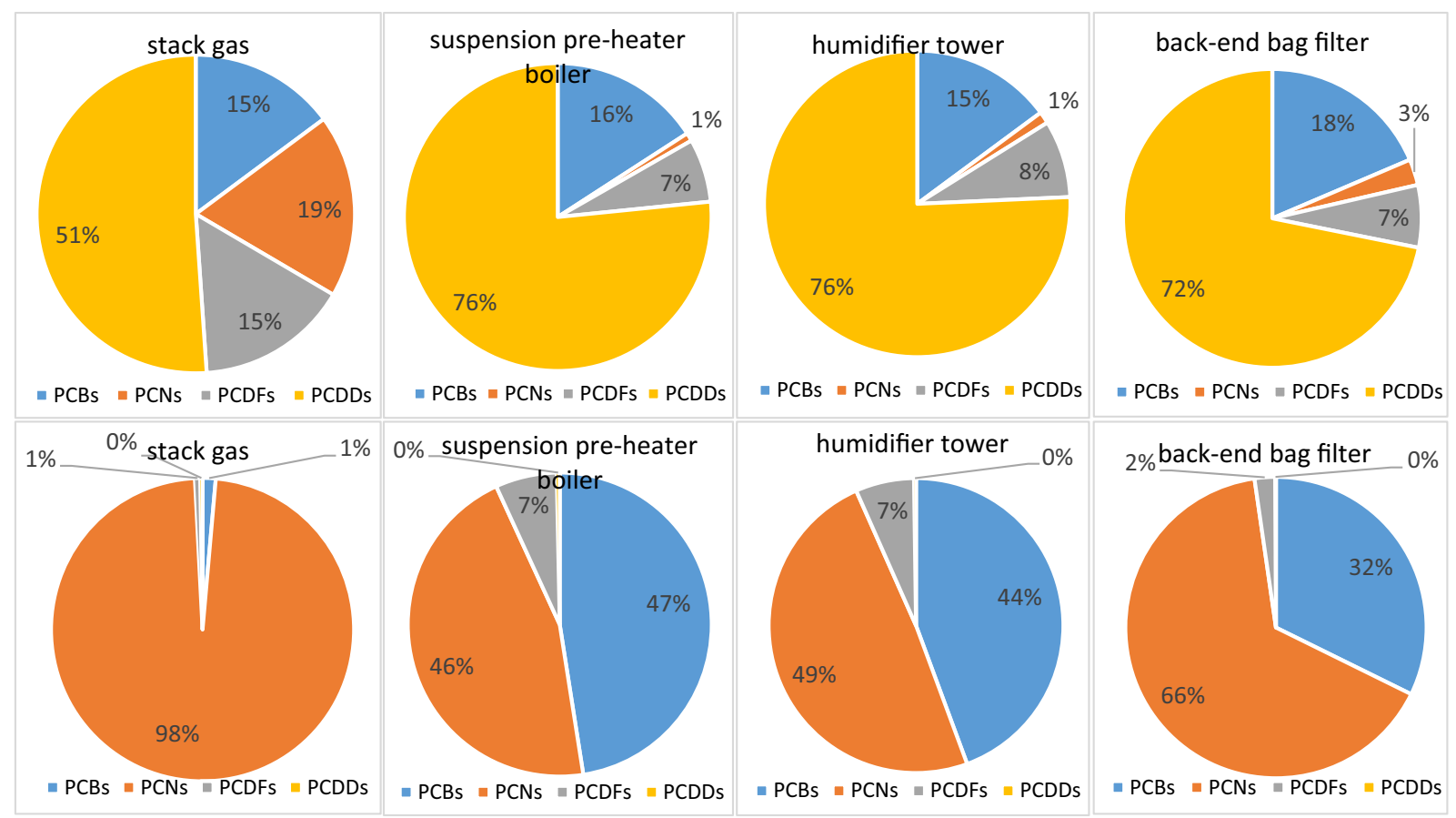

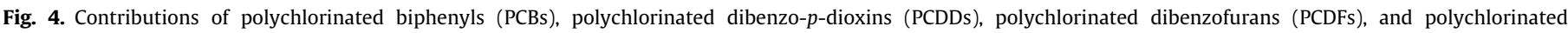

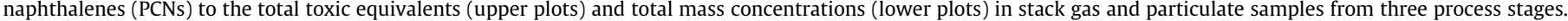
The PCDD, PCDF, and PCN data are from previous publications (Liu et al., 2015, 2016).

\subsection{Mass balance of PCBs in the cement kiln system}

This field study was performed in a cement plant on industrial scale. The capacity of cement kiln 1 was $2000 \mathrm{t}$ per day. PCBs are highly toxic pollutants that are present at trace levels (typically $10^{-12} \mathrm{~g} / \mathrm{g}$ ) in samples from industrial sources. Because of the industrial scale and trace levels, stoichiometric mass balances for specific chemical reactions associated with PCB formation could not be achieved in the field study. However, a mass balance calculated by comparing the input and output of unintentionally produced POPs could improve our understanding of the net emissions of POPs from cement kilns co-processing MSWI fly ash (Liu et al., 2015, 2016). We have previously reported mass balances for PCDD/Fs and PCNs in cement kilns co-processing MSWI fly ash. In our previous mass balances, we found that the net release rate for seventeen 2,3,7,8-chlorinated PCDD/Fs from a cement kiln system was $-9295 \mu \mathrm{g} \mathrm{h}^{-1}$ or $-640 \mu \mathrm{g} \mathrm{TEQ} \mathrm{h}{ }^{-1}$ (Liu et al., 2015). In that earlier study, the masses of different PCDD/F congeners in cement kiln outputs were between 50\% and 99\% lower than the masses of the congeners added to the kiln as raw materials (Liu et al., 2015). In terms of TEQ, the PCDD/F output was about $94 \%$ lower than the input (Liu et al., 2015). The net PCN release rate was $-196 \mathrm{mg} \mathrm{h}^{-1}$, and the output of PCN congeners from the kiln was about half of the mass in the raw materials added to the kiln (Liu et al., 2016).

In this study, we also calculated PCB mass balances using the PCB concentrations in the feed stocks, stack gas samples, and clinker, and the cement production activity parameters that we have published previously (Liu et al., 2015, 2016). The PCB mass concentration in the MSWI fly ash that was fed into the cement kilns was $31.8 \mathrm{ng} \mathrm{g}^{-1}$. The PCB mass concentrations in the raw meal and coal powder were 13.9 and $50.0 \mathrm{ng} \mathrm{g}^{-1}$, respectively. The relatively high PCB mass concentrations found in the coal powder were assumed to have been caused by PCBs in the hot gas from the cyclone preheater outlet that was used to dry the wet coal powder. We found relatively high $\mathrm{PCDD} / \mathrm{F}$ and $\mathrm{PCN}$ mass concentrations in coal pow- der in our previous studies, possibly for the same reason (Liu et al., 2015, 2016). The PCB mass balances for the kiln system are shown in Table S2. The net emission of PCBs by the cement kilns was $-1589 \mathrm{mg} \mathrm{h}^{-1}$. About half of PCBs (by mass) added to the kiln in the raw materials were emitted. Compared to our earlier results, this was comparable to the proportion of PCNs emitted, but lower than the proportion of PCDD/Fs emitted by the kiln system (Liu et al., 2015, 2016).

\subsection{Comparison of mass and TEQ contributions for PCBs, PCNs, PCDDs, and PCDFs}

PCBs are structurally and toxicologically similar to PCNs, PCDDs, and PCDFs. The TEFs of PCB and PCN congeners relative to 2,3,7,8tetrachlorodibenzo- $p$-dioxin have been estimated and can be used to compare the contributions of different $\mathrm{PCB}, \mathrm{PCN}$, and $\mathrm{PCDD} / \mathrm{F}$ congeners to the total dioxin-like toxicity of a mixture (Van den Berg et al., 1998; Blankenship et al., 2000; Villeneuve et al., 2000; Noma et al., 2004; Falandysz et al., 2013. Falandysz et al. (2013) recently evaluated and updated the PCN TEFs (Falandysz et al., 2013). Comparisons of the contributions of different POPs to the total mass concentrations and total TEQs are useful for understanding the priority of POPs. Rivera-Austrui et al. found that the contribution of PCBs to total TEQs of PCBs plus PCDD/Fs was about $25 \%$ for stack gas from a clinker kiln using alternative fuels (Rivera-Austrui et al., 2014).

In the present study, the contributions to mass concentrations and TEQs of PCBs, PCNs, PCDDs, and PCDFs in the stack gas and the particulate samples from the three main stages for POP formation were compared (Fig. 4) (Liu et al., 2015, 2016). PCNs were the dominant POPs in the stack gas samples, contributing to about $98 \%$ of the total PCB, PCN, PCDD, and PCDF mass concentrations. The PCNs contributed about 19\% of the TEQs for the stack gas samples, which was slightly more than the PCB contribution (15\%) and the PCDF contribution (15\%) but lower than the PCDD contribution (51\%). The contribution (15\%) of PCBs to total TEQ was slightly 
lower than that reported for stack gas from a clinker kiln using alternative fuels (Rivera-Austrui et al., 2014). The PCNs contributed $46-66 \%$ of the total PCB, PCN, PCDD, and PCDF mass concentrations in the particulate samples from the three stages, whereas the PCBs contributed $32-47 \%$, and the PCDDs and PCDFs both contributed less than $10 \%$. The TEFs for the PCDDs were higher than the TEFs for the PCBs and PCNs, and the PCDDs contributed $72-76 \%$ of the total TEQs in the particulate samples. The PCBs contributed 15$18 \%$ of the total TEQs in the particulate samples, which was more than the combined contribution of the PCDFs and PCNs.

\section{Conclusions}

The PCB concentrations and homolog and congener patterns in stack gas and particulate samples from two cement kilns showed PCBs mainly formed at the same sites as PCDD/Fs and PCNs. This indicates that PCBs, PCDD/Fs, and PCNs are formed in similar ways in cement kilns. Therefore, it should be possible to simultaneously reduce the formation and emission of multiple POPs. The PCBs contributed more than the PCDFs and PCNs to the total TEQs of the PCBs, PCDD/Fs, and PCNs in the particulate samples at the three main stages for POP formation. A mass balance of PCBs in the cement kilns showed that the total mass of PCBs in the kiln stack gases and clinker was half the mass of PCBs in the raw materials. The results for the two kilns suggested that periodically removing solid residues deposited at the main stages for POP formation could reduce further formation of $\mathrm{PCBs}, \mathrm{PCDD} / \mathrm{Fs}$, and $\mathrm{PCNs}$ at those sites.

\section{Acknowledgments}

This work was supported by the Chinese National 973 program (grant number 2015CB453100), the National Natural Science Foundation of China (grant number 91543108) and the Youth Innovation Promotion Association of the Chinese Academy of Sciences (grant number 2016038).

\section{Appendix A. Supplementary material}

Supplementary data associated with this article can be found, in the online version, at http://dx.doi.org/10.1016/j.wasman.2016.09. 010.

\section{References}

Abad, E, Caixach, J. Rivera, J. 1999. Dioxin like compounds from municipal waste incinerator emissions: Assessment of the presence of polychlorinated naphthalenes. Chemosphere 38, 109-120.

Ba, T., Zheng, M.H., Zhang, B., Liu, W.B., Su, G.J., Liu, G.R., Xiao, K., 2010. Estimation and congener-specific characterization of polychlorinated naphthalene emissions from secondary nonferrous metallurgical facilities in China. Environ. Sci. Technol. 44, 2441-2446.

Blankenship, A.L, Kannan, K. Villalobos, S.A. Villeneuve, D.L, Falandysz, J. Imagawa, T., Jakobsson, E., Giesy, J.P., 2000. Relative potencies of individua polychlorinated naphthalenes and halowax mixtures to induce Ah receptormediated responses. Environ. Sci. Technol. 34, 3153-3158.

Breivik, K., Sweetman, A., Pacyna, J.M., Jones, K.C., 2007. Towards a global historical emission inventory for selected PCB congeners - a mass balance approach-3. An update. Sci. Total Environ. 377, 296-307.

Conesa, J.A., Rey, L., Egea, S., Rey, M.D., 2011. Pollutant formation and emissions from cement kiln stack using a solid recovered fuel from municipal solid waste. Environ. Sci. Technol. 45, 5878-5884.

Cunliffe, A.M., Williams, P.T., 2009. De-novo formation of dioxins and furans and the memory effect in waste incineration flue gases. Waste Manage. (Oxford) 29, 739-748.

Diamond, M.L., Melymuk, L., Csiszar, S.A., Robson, M., 2010. Estimation of PCB stocks, emissions, and urban fate: will our policies reduce concentrations and exposure? Environ. Sci. Technol. 44, 2777-2783.

Falandysz, J., Fernandes, A., Gregoraszczuk, E.M.R., 2013. Aryl hydrocarbon receptor mediated (dioxin-like) relative potency factors for chlornaphthalenes. Organohalogen Compd. 75, 336-338.

Garcia-Perez, J., Lopez-Abente, G., Castello, A., Gonzalez-Sanchez, M., FernandezNavarro, P., 2015. Cancer mortality in towns in the vicinity of installations fo the production of cement, lime, plaster, and magnesium oxide. Chemosphere $128,103-110$

Hornbuckle, K., Robertson, L., 2010. Polychlorinated biphenyls (PCBs): sources, exposures, toxicities. Environ. Sci. Technol. 44, 2749-2751.

Hu, D.F. Hornbuckle, K.C., 2010. Inadvertent polychlorinated biphenyls in commercial paint pigments. Environ. Sci. Technol. 44, 2822-2827.

Jansson, S., Andersson, P.L., 2012. Relationships between congener distribution patterns of PCDDs, PCDFs, PCNs, PCBs, PCBzs and PCPhs formed during flue gas cooling. Sci. Total Environ. 416, 269-275.

Jansson, S., Fick, J., Marklund, S., 2008. Formation and chlorination of polychlorinated naphthalenes (PCNs) in the post-combustion zone during MSW combustion. Chemosphere 72, 1138-1144.

Jiang, X.X., Liu, G.R., Wang, M., Zheng, M.H., 2015a. Fly ash-mediated formation of polychlorinated naphthalenes during secondary copper smelting and mechanistic aspects. Chemosphere 119, 1091-1098.

Jiang, X.X., Liu, G.R., Wang, M., Zheng, M.H., 2015b. Formation of Polychlorinated Biphenyls on Secondary Copper Production Fly Ash: Mechanistic Aspects and Correlation to Other Persistent Organic Pollutants. Sci Rep-Uk 5.

Khumsaeng, T., Oanh, N.T.K., Kare, K.H., Polprasert, C., 2013. Emission of dioxins/furans and other U-POPs from test burns of non-POP pesticides in a hazardous waste incinerator. Waste Manage. (Oxford) 33, 833-841.

Li, H.W., Wang, L.C., Chen, C.C., Yang, X.Y., Chang-Chien, G.P., Wu, E.M.Y., 2011. Influence of memory effect caused by aged bag filters on the stack PCDD/F emissions. J. Hazard. Mater. 185, 1148-1155.

Liu, G.R., Liu, W.B., Cai, Z.W., Zheng, M.H., 2013a. Concentrations, profiles, and emission factors of unintentionally produced persistent organic pollutants in fly ash from coking processes. J. Hazard. Mater. 261, 421-426.

Liu, G.R., Zhan, J.Y., Zhao, Y.Y., Li, L., Jiang, X.X., Fu, J.J., Li, C.P., Zheng, M.H., 2016. Distributions, profiles and formation mechanisms of polychlorinated naphthalenes in cement kilns co-processing municipal waste incinerator fly ash. Chemosphere 155, 348-357.

Liu, G.R., Zhan, J.Y., Zheng, M.H., Li, L., Li, C.P., Jiang, X.X., Wang, M., Zhao, Y.Y., Jin, R., 2015. Field pilot study on emissions, formations and distributions of PCDD/Fs from cement kiln co-processing fly ash from municipal solid waste incinerations. J. Hazard. Mater. 299, 471-478.

Liu, G.R., Zheng, M.H., Cai, M.W., Nie, Z.Q., Zhang, B., Liu, W.B., Du, B., Dong, S.J., Hu, J. C., Xiao, K., 2013b. Atmospheric emission of polychlorinated biphenyls from multiple industrial thermal processes. Chemosphere 90, 2453-2460.

Liu, G.R., Zheng, M.H., Liu, W.B., Wang, C.Z., Zhang, B., Gao, L.R., Su, G.J., Xiao, K., Lv, P., 2009. Atmospheric emission of $\mathrm{PCDD} / \mathrm{Fs}$, PCBs, hexachlorobenzene, and pentachlorobenzene from the coking industry. Environ. Sci. Technol. 43, 91969201.

Liu, G.R., Zheng, M.H., Lv, P., Liu, W.B., Wang, C.Z., Zhang, B., Xiao, K., 2010. Estimation and characterization of polychlorinated naphthalene emission from coking industries. Environ. Sci. Technol. 44, 8156-8161.

Lv, P., Zheng, M.H., Liu, G.R., Liu, W.B., Xiao, K., 2011. Estimation and characterization of PCDD/Fs and dioxin-like PCBs from Chinese iron foundries. Chemosphere 82, 759-763.

Nie, Z.Q., Liu, G.R., Liu, W.B., Zhang, B., Zheng, M.H., 2012. Characterization and quantification of unintentional POP emissions from primary and secondary copper metallurgical processes in China. Atmos. Environ. 57, 109-115.

Nie, Z.Q., Zheng, M.H., Liu, W.B., Zhang, B., Liu, G.R., Su, G.J., Lv, P., Xiao, K., 2011. Estimation and characterization of PCDD/Fs, dl-PCBs, PCNs, $\mathrm{HxCBz}$ and PeCBz emissions from magnesium metallurgy facilities in China. Chemosphere 85, 1707-1712.

Noma, Y., Yamamoto, T., Sakai, S.I., 2004. Congener-specific composition of polychlorinated naphthalenes, coplanar PCBs, dibenzo-p-dioxins, and dibenzofurans in the halowax series. Environ. Sci. Technol. 38, 1675-1680.

Rivera-Austrui, J., Martinez, K., Marco-Almagro, L., Abalos, M., Abad, E., 2014. Longterm sampling of dioxin-like substances from a clinker kiln stack using alternative fuels. Sci. Total Environ. 485, 528-533.

Sakai, S., Yamamoto, T., Noma, Y., Giraud, R., 2006. Formation and control of toxic polychlorinated compounds during incineration of wastes containing polychlorinated naphthalenes. Environ. Sci. Technol. 40, 2247-2253.

Schuhmacher, M., Bocio, A., Agramunt, M.C., Domingo, J.L., de Kok, H.A.M., 2002. $\mathrm{PCDD} / \mathrm{F}$ and metal concentrations in soil and herbage samples collected in the vicinity of a cement plant. Chemosphere 48, 209-217.

Schuhmacher, M., Domingo, J.L., Garreta, J., 2004. Pollutants emitted by a cement plant: health risks for the population living in the neighborhood. Environ. Res. 95, 198-206.

Tabata, M., Ghaffar, A., Shono, A., Notomi, K., 2013. Hydrodechlorination/ detoxification of PCDDs, PCDFs, and Co-PCBs in fly ash by using calcium polysulfide. Waste Manage. (Oxford) 33, 356-362.

Van den Berg, M., Birnbaum, L., Bosveld, A.T.C., Brunstrom, B., Cook, P., Feeley, M., Giesy, J.P., Hanberg, A., Hasegawa, R., Kennedy, S.W., Kubiak, T., Larsen, J.C., van Leeuwen, F.X.R., Liem, A.K.D., Nolt, C., Peterson, R.E., Poellinger, L., Safe, S. Schrenk, D., Tillitt, D., Tysklind, M., Younes, M., Waern, F., Zacharewski, T., 1998. Toxic equivalency factors (TEFs) for PCBs, PCDDs, PCDFs for humans and wildlife. Environ. Health Perspect. 106, 775-792.

Villeneuve, D.L., Kannan, K., Khim, J.S., Falandysz, J., Nikiforov, V.A., Blankenship, A. L., Giesy, J.P., 2000. Relative potencies of individual polychlorinated naphthalenes to induce dioxin-like responses in fish and mammalian in vitro bioassays. Arch. Environ. Con. Tox. 39, 273-281.

Wang, M., Liu, G.R., Jiang, X.X., Xiao, K., Zheng, M.H., 2015. Formation and potential mechanisms of polychlorinated dibenzo-p-dioxins and dibenzofurans on fly ash 
from a secondary copper smelting process. Environ. Sci. Pollut. Res. 22, 8747 8755.

Weber, R., Sakurai, T., Ueno, S., Nishino, J., 2002. Correlation of PCDD/PCDF and CO values in a MSW incinerator - indication of memory effects in the high temperature/cooling section. Chemosphere 49, 127-134.

Wurst, F., Prey, T., 2003. Dioxin emissions when using alternative fuels in the cement industry. Zkg Int. 56, 74-77.
Yang, Y.F., Huang, Q.F., Tang, Z.W., Wang, Q., Zhu, X.H., Liu, W.B., 2012. Decabrominated diphenyl ether destruction and $\mathrm{PBDD} / \mathrm{F}$ and $\mathrm{PCDD} / \mathrm{F}$ emissions from coprocessing deca-BDE mixture-contaminated soils in cement kilns. Environ. Sci. Technol. 46, 13409-13416.

Zhang, Z., Oi, H., Liu, L.Y., Meng. Y., Li, Y.F, 2009. Congener and homologue profiles of polychlorinated biphenyls (PCBs) produced in China. J. Nat. Sci. Heilongjiang Univ. 26, 809-815 (In Chinese). 